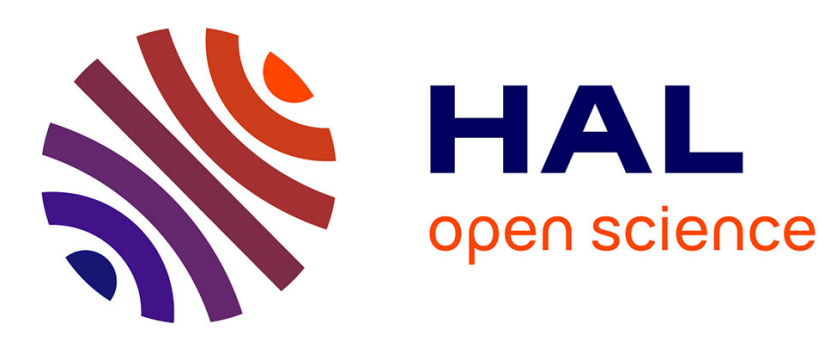

\title{
Mechanical behavior of polystyrene grafted carbon nanotubes/polystyrene nanocomposites
}

Benjamin Fragneaud, Karine Masenelli-Varlot, A. Gonzalez-Montiel, H. Terrones, Jean-Yves Cavaille

\section{- To cite this version:}

Benjamin Fragneaud, Karine Masenelli-Varlot, A. Gonzalez-Montiel, H. Terrones, Jean-Yves Cavaille. Mechanical behavior of polystyrene grafted carbon nanotubes/polystyrene nanocomposites. Composites Science and Technology, 2008, 68 (15-16), pp.3265-3271. 10.1016/j.compscitech.2008.08.013 . hal-00433976

\section{HAL Id: hal-00433976 https://hal.science/hal-00433976}

Submitted on 13 Jun 2019

HAL is a multi-disciplinary open access archive for the deposit and dissemination of scientific research documents, whether they are published or not. The documents may come from teaching and research institutions in France or abroad, or from public or private research centers.
L'archive ouverte pluridisciplinaire HAL, est destinée au dépôt et à la diffusion de documents scientifiques de niveau recherche, publiés ou non, émanant des établissements d'enseignement et de recherche français ou étrangers, des laboratoires publics ou privés. 
Mechanical behavior of polystyrene grafted carbon nanotubes / polystyrene nanocomposites

B. Fragneaud ${ }^{a, b, *}$, K. Masenelli-Varlot ${ }^{a}$, A. Gonzalez-Montiel ${ }^{b}$, M. Terrones ${ }^{c, d}$, J.Y. Cavaillé $^{a}$.

${ }^{a}$ MaterialsEngineering \& Science (MATEIS, ex GEMPPM), INSA-Lyon, CNRS UMR5510, 69621

Villeurbanne cedex, France.

${ }^{\mathrm{b}}$ Centro de Investigación y Desarrollo tecnológico del grupo DESC, Av de los sauces 83 Mza, 6

Parque Industrial Lerma, Lerma, Edo.Mex, México.

${ }^{\mathrm{c}}$ Instituto Potisino de Investigación Cientifica y Tecnológica, A.C. Camino a la Presa San José 2055

Col. Lomas 4 Sección, C.P. 78216 San Luis Potosí, México.

${ }^{\mathrm{d}}$ International Center for Young Scientists (ICYS), National Institute for Materials Science, Namiki 1-1, Tsukuba, Ibaraki 305-0044, Japan

${ }^{*}$ Corresponding author: B. Fragneaud (bf2204@columbia.edu); New address: Mechanical Engineering Department, Columbia University, 220 SW Mudd Building, $120^{\text {th }}$ street, New York, NY, 10027

Keywords: Coupling agent; plastic deformation; debonding; fracture; modeling

\begin{abstract}
This study is concerned with the improvement of interfacial adhesion in polystyrene carbon nanotubes composites by grafting polystyrene chains onto the nanotube surface. Based upon a previously described method (Fragneaud et al., Chem Phys Lett 419 (2006) 567-573), the polystyrene was covalently bond onto the nanotube surface with an average molecular weight of about $10^{4} \mathrm{~g} \cdot \mathrm{mol}^{-1}$ from which composites with different nanotube weight fraction were synthesized. The grafting efficiency, has been extrapolated from dynamic stress-strain data in the linear viscoelastic domain (below and above $\mathrm{Tg}$ ) as the same as using compressive tests below $\mathrm{Tg}$. In this work, it is shown that short chains polymer grafting, (i) enhanced the dispersion of the nanotubes within the matrix, (ii) increased the Young modulus below Tg, and (iii) increased the stress breaking of the nanocomposites. We also note that the low molecular weight grafting plasticizes the matrix near the nanotube surface. The linear viscoelastic behavior is compared with predictions from a mechanical coupling model. Finally, the role of the nanotube waviness, percolation, as well as the entanglement is discussed.
\end{abstract}




\section{$\underline{\text { Introduction }}$}

The last two decades, various scientists focused their efforts on nanotube synthesis and on their applications. Numerous review articles about nanotubes properties point out their particular intrinsic physical properties, such as good electrical and thermal conductivity ${ }^{1}$ and Young modulus up to 1 TPa for single-wall nanotubes (SWNTs) ${ }^{2}$. Their high aspect ratio also predicts a very low volume fraction to reach percolation threshold. The surface of nanotubes, both SWNT and multiwall CNT (MWNT), exhibits characteristics close to that of neutral graphite, which make them difficult to disperse in liquids. This phenomenon must be avoided for the processing of polymer composites, and the addition of functional groups on the nanotube surface is elegant route to modify its chemical activity in order to selectively disperse the tubes in a particular medium ${ }^{3,4}$. One way to maximize the dispersion of CNTs in a solvent can be achieved by grafting polymer chains on their outer surface ${ }^{5}$. A recent and novel approach to the growth of polymer chains from solid surfaces, is based on Atomic Transfer Radical Polymerization (ATRP) ${ }^{6}$. Previous studies have demonstrated the efficiency of this technique to cover the outer layer of N-doped multiwall carbon nanotubes (so called here after CNx MWNT) with a thin layer of PS ${ }^{7}$.

The literature presents numerous studies related to the mechanical properties of polymer / carbon nanotubes composites materials. By adding carbon nanotubes to a polymer matrix, an increase of the Young modulus and tensile strength of the composite is expected. Nevertheless, data from the literature is conflicting and reports Young modulus enhancement from some percent to a factor $3^{8-13}$. It has also been shown that nanotubes act as a nucleant agent within some semi-crystalline polymer matrices ${ }^{14-16}$. In such conditions, the matrix crystallinity ratio increases which makes it more difficult to distinguish the reinforcement due to the nanotubes load transfer from that of the matrix crystallization. Finally, each system, depending on its physical-chemical properties seems to have its own reinforcement mechanism. Nevertheless some theoretical calculations ${ }^{14,17}$ predict results in good agreement with experimental data for low volume fractions of aligned nanotubes $(<2.5 \%)$. But most of the time the experimental load transfer is lower than that predicted by theoretical calculations because such models employ stiff rods rather than flexible fibers. On the 
other hand, the bad dispersion state (presence of aggregates) as well as the poor matrix / filler adhesion are responsible for the poor experimental mechanical properties ${ }^{9,17}$. A review from $\mathrm{J}$. Coleman, on carbon nanotube / polymer composites, summarizes the results for a large number of works concerning such composites ${ }^{15}$. In this review paper two types of polymer grafting strategies are reported: "grafting to" and "grafting from". The "grafting from" technique is a more efficient process in order to obtain a dense layer grafted onto the surface of the carbon nanotube ${ }^{7,18}$. At low volume fractions (i.e. 0.008 vol.\%), polymer grafted nanotubes provide a mechanical reinforcement close to the theoretical prediction of mixture rule for well aligned and well graphitized tubes ${ }^{19}$. In this work we studied the effect of N-doped multiwall carbon nanotubes (CNx MWNT) as mechanical fillers in a polystyrene (PS) matrix. CNx MWNTs were introduced without any chemical treatment (referred to as a-CNx), or with a grafted polystyrene layer on the external sidewall of the CNx MWNTs (referred to as PS-g-CNx). This article focuses on the impact of CNTs chemical functionnalization over mechanical properties of carbon nanotube composites.

\section{$\underline{\text { Experimental part }}$}

CNx Nanotube Synthesis: as described elsewhere, the N-doped tubes were produced using a CVD process involving solutions containing $2.5 \mathrm{wt} \%{ }^{20}$ of ferrocene $\left(\mathrm{FeCp}_{2}\right)$ in benzylamine $\left(\mathrm{C}_{7} \mathrm{H}_{9} \mathrm{~N}\right)$. The solution was then atomized using an abrupt Ar pressure difference. This generated an aerosol that was then conducted into a quartz tube heated to $850{ }^{\circ} \mathrm{C}$ in the presence of Ar. The nanotube growth occurred for 15 minutes and after allowing the system to cool down to room temperature, nanotubes were extracted from the reaction zone inside the quartz tube.

Nanotube Functionalisation: as presented in previous study ${ }^{7}, \mathrm{CNx}^{\mathrm{MWNT}}$ were functionalized using a free radical process. Benzoil peroxide was added to a solution of CNx-MWNTs in toluene. The reaction was conducted at $105^{\circ} \mathrm{C}$, after which the CNx-MWNTs were collected by filtering and washed with reactive grade toluene. The residual solvent was removed by evaporation at $100^{\circ} \mathrm{C}$ $(373 \mathrm{~K})$ under vacuum. Then, the aromatic rings grafted on the surface of the tubes, were brominated with $\mathrm{Br}_{2}$, using $\mathrm{FeBr}_{3}$ as catalyst and $\mathrm{CCl}_{4}$ as solvent. After filtration and washing, the material was dried at $100^{\circ} \mathrm{C}$ under vacuum. 
Polystyrene-grafted $C N x M W N T^{7}$ : the functionalized nanotubes were used to initiate the ATRP

reaction. Previous work has shown that the functional halogenated groups can generate free radicals due to a redox process that allows ATRP ${ }^{6}$. A solution of ligand-catalyst in toluene was prepared with $\mathrm{CuBr}(\mathrm{I})$ and 4,4'-dinonyl 2,2'-bipyridine (dNbpy). Functionalized $\mathrm{CNx}$ MWNTs were dispersed, with the metal ligand complex catalyst, in a mixture of toluene and styrene. The polymer grafted CNx-MWNTs were then precipitated in ethanol. Finally, the treated CNx MWNTs were filtered and the material was washed with an excess of toluene. This method enables the synthesis of nanotubes covered by a covalently bond PS layer. Thermo Gravimetric Analysis of such processed CNx MWNTs showed weight losses of $40 \%$ attributed to the PS layer the other $60 \%$ corresponding to the CNTs.

Scanning Electronic Microscopy: the PS-based nanocomposites were fractured at room temperature. The fracture surfaces were observed without any metal coating with a FEI ESEM XL30-FEG under high vacuum. The accelerating voltage was set to $800 \mathrm{~V}$. Secondary electrons were used to form the images.

Polymer nanocomposite preparation: two types of nanocomposites were prepared, using polystyrene (PS, resin HH-104 from Resirene) as matrix, and either as-produced CNx MWNTs, or PS-graftedCNx MWNTs. The CNx MWNTs were sonicated for 20 minutes in toluene. Subsequently, polystyrene was added to the solution and stirred two hours. The magnetic stirring was maintained while the solvent was evaporated using an air flow over the solution. Finally, the residual solvent was evaporated under vacuum by heating at $110^{\circ} \mathrm{C}(383 \mathrm{~K})$ for 48 hours. The PS grafted $\mathrm{CNx}$ MWNTs were dispersed by stirring in toluene for 8 hours. Then, the same process as described above was used to disperse the nanotubes within the matrix. Films of about $0.6 \mathrm{~mm}$ to $0.8 \mathrm{~mm}$ thickness were obtained by pressing the nanocomposites for $15 \mathrm{~min}$ at a temperature higher than the PS' Tg, i.e. at $150^{\circ} \mathrm{C}(423 \mathrm{~K})$.

Differential Scanning Calorimetry: the samples were submitted to DSC experiments using a temperature rate of $1 \mathrm{~K} / \mathrm{min}$., with a nitrogen gas flow of $40 \mathrm{ml} / \mathrm{min}$. 
Dynamic mechanical analysis: a updated homemade device at MATEIS (France), based on a reliable series of setup was used ${ }^{21}$. A magnet between two Helmholtz coils where an alternative current is injected creates the shear stress. The torque is transmitted to the sample by a metallic hard stick. The material strain is detected by a reflected laser diode and transmitted to the computer interface for calculation. This device has the ability to measure the complex mechanical modulus with a very high accuracy with sample thickness section dimensions ranging from $100 \mu \mathrm{m}$ to few $\mathrm{mm}$. All the measurements were carried out at $1 \mathrm{~Hz}$, using a heating rate of $3 \mathrm{~K} / \mathrm{min}$.

\section{- Compression Tensile Tests}

The compression tests were performed using an INSTRON standard mechanical testing machine equipped with parallel platens. The samples consisted of cylinders with a diameter of $4.5 \mathrm{~mm}$ and a length of $8 \mathrm{~mm}$; the diameter/length ratio avoid undesirable deformations such as buckling. Furthermore, in order to restrain barreling effect, the contact surfaces of the sample were polished and lubricated with molybdenum disulphide $\left(\mathrm{MoS}_{2}\right)$. To ensure an accurate measurement of the strain, we used a video device which is able to follow the deformation of the samples, using marks previously etched. A simple calculation from the data collected during the experiments permits an accurate determination of the nominal stress. The true strain was determined by the classical relationship:

$$
\varepsilon=\operatorname{Ln} \frac{l}{l_{0}}
$$

where $l_{0}$ refers to the initial length of the sample, and $l$ to its current length during the test. The strain rate was of $10^{-4} \mathrm{~s}^{-1}$.

\section{$\underline{\text { Results and discussions }}$}

\section{Glass transition temperature of the CNx MWNT / PS nanocomposites.}

Differential Scanning Calorimetry allows to distinguish the influence of CNx MWNT surface polymer grafting form the polystyrene matrix glass transition temperature. Figure 1 shows the results obtained for different combinations of materials. Pure PS exhibits a glass transition at $99^{\circ} \mathrm{C}(372 \mathrm{~K})$, in agreement with values reported in the literature ${ }^{22}$. Nanocomposites with as high as 2.5 vol. \% of as-received $\mathrm{CN}_{\mathrm{X}}$ MWNTs do not exhibit a significant change in the matrix glass transition found at 
$98^{\circ} \mathrm{C}(371 \mathrm{~K})$. Nevertheless, polymer grafted nanotubes (without PS matrix) has a lower glass transition temperature of $83{ }^{\circ} \mathrm{C}(356 \mathrm{~K})$. It is well known ${ }^{22}$ that the polystyrene glass transition temperature $\mathrm{Tg}$ is almost constant for molecular weight $(\overline{\mathrm{Mn}})$ over $10^{5} \mathrm{~g} \cdot \mathrm{mol}^{-1}$. Below this value, the glass transition temperature starts to decrease, following an empirical relation such as:

$$
T g=T g_{\infty}-\frac{k}{\overline{M w}}
$$

where $\mathrm{k}$ is a constant $\left(\approx 1.710^{5}\right.$ for PS) and $\mathrm{Tg}_{\infty}$ refers to the $\mathrm{Tg}$ for very large $\overline{\mathrm{Mw}}$. Notice that the pristine PS matrix has a molecular weight of $5 \cdot 10^{5} \mathrm{~g} \cdot \mathrm{mol}^{-1}$. As a consequence of eqn. 2, we attribute the low glass transition temperature observed for $100 \%$ of PS-g-CNx MWNTs to small polystyrene molecular weight. From eqn. 2 we infer the molecular weight of the nanotube surface grown polystyrene should be about $10^{4} \mathrm{~g} \cdot \mathrm{mol}^{-1}$. It is consistent with the work of Matyjaszewski and Xia ${ }^{6}$, who showed that ATRP grown polystyrene generally have low molecular weights. Finally, nanocomposites with $2.5 \%$ vol. of PS-g-CN $\mathrm{C}_{\mathrm{X}}$ MWNTs exhibit a glass transition temperature shifted down to $92^{\circ} \mathrm{C}(365 \mathrm{~K})$ and in the range of $80^{\circ} \mathrm{C}$ to $99^{\circ} \mathrm{C}(353 \mathrm{~K}$ to $372 \mathrm{~K})$. It is noteworthy that the transition is much wider (about twice as much) than for pure PS. If we assume that the PS grafted layer acts as a plasticizer within the bulk PS, we expect the matrix nearby the PS grafted layer to have a lower Tg. On the other hand the matrix far away from the PS grafted layer should not be affected. This gradient of molecular mobility is observed in the DSC thermogram as a wider transition. This transition should start from temperatures corresponding to the PS grafted layer glass transition until the temperature of the bulk PS matrix glass transition. Nevertheless, for composites with $2.5 \%$ vol. PS-g-CN $\mathrm{CN}_{\mathrm{X}}$ MWTs, we observed that the glass transition range is overall shifted to lower temperatures $\left(80^{\circ} \mathrm{C}\right.$ to $99^{\circ} \mathrm{C}$, i.e. $353 \mathrm{~K}$ to $\left.372 \mathrm{~K}\right)$ whereas bulk PS glass transition ranges from $90^{\circ} \mathrm{C}$ to $105^{\circ} \mathrm{C}(363 \mathrm{~K}$ to $378 \mathrm{~K})$. Therefore, the entire matrix is almost plasticized by the grafted PS, which suggests that the average distance between carbon nanotubes is smaller than the interphase thickness, which indicates that the nanotubes are well dispersed. 


\section{Elastic properties of the PS/CNx MWNTs composites}

Young moduli were determined with compressive tensile test curves obtained at ambient temperature (Table1). Pristine PS Young's modulus was measured at $2.02 \mathrm{GPa}$. With 2.5 vol.\% of as received $\mathrm{CN}_{\mathrm{X}}$ MWNTs we observed a Young's modulus increase of 20\% (2.5 GPa) which is consistent with in the literature ${ }^{8,12}$. On the other hand, 2.5 vol.\% PS-g-CNx MWNTs composites show a Young's modulus increase of 33\% (2.72 GPa). The literature reports numerous references that demonstrate a reinforcement of polymers by introducing MWNTs or SWNTs ${ }^{8,12,15,23}$. Indeed, it has been shown that the high aspect ratio of the MWNT, and its very high interface area allow a better mechanical reinforcement than with carbon black fillers ${ }^{12,23}$. Nevertheless, experimental results obtained are weaker than those expected by theoretical calculations. Odegard et al. ${ }^{17}$, using molecular dynamics and an equivalent-continuum model, overestimate by about $300 \%$ the elastic modulus for a composite with $5 \%$ of randomly dispersed carbon nanotubes. One possible explanation is the poor dispersion of carbon nanotubes that may minimize the effect of carbon nanotube mechanical reinforcement ${ }^{12,16}$. Figure 2 shows SEM photomicrographs of the nanocomposites with PS-g- $\mathrm{CN}_{\mathrm{x}}$ (Figure 2a) and a-CN $\mathrm{CN}_{\mathrm{x}}$ MWNTs (Figure 2b). Both contain 2.5 vol.\% of nanotubes. The fracture surface of these two materials was observed after fracture at room temperature. The polystyrene grafting seems to lead to a better dispersion of the nanotubes within the PS matrix and only small heterogeneities can be seen, whereas larger agglomerations (up to $10 \mu \mathrm{m})$ are observed in composites containing $\mathrm{a}-\mathrm{CN}_{\mathrm{x}}$ (see for example near the center of Figure $2 \mathrm{~b}$ ). These agglomerations result in a poor $\mathrm{CN}_{\mathrm{X}} \mathrm{MWNT} /$ matrix adhesion and lead to lower load transfer. This can in fact explain the differences between our experimentally measured Young's Modulus. Indeed, PS-g-CNx MWNTs are better dispersed and thus permit a larger matrix / filler contact area. Also, load transfer might increase because of a better interface between the matrix and the filler.

The Halpin Kardos (HK equation) model was developed to predict the reinforcement of matrices by stiff straight rods. The HK approach ${ }^{24}$ reformulates the Halpin-Tsai equation considering four layers oriented at $0^{\circ},+45^{\circ}, 90^{\circ},-45^{\circ}$. Nevertheless this model is not perfectly adapted to our system, since 
nanotubes are rather flexible with a low bending modulus $(\approx 20 \mathrm{GPa})$. To date, there is no suitable analytical mechanical coupling model to predict the reinforcement in composites accounting for fiber waviness. The HK equation requires several parameters such as the fiber shear and tension moduli, the matrix shear modulus (supposed to be isotropic), the fibers volume fraction as well as their aspect ratios. As a first attempt, we used (i) a longitudinal modulus of $750 \mathrm{GPa}$ (according to Hernandez et al. ${ }^{25}$ ) and (ii) the nanotube aspect ratio (f) was considered as an adjustable parameter. The volume fraction of grafted carbon nanotubes used for the calculation does not account for the grafted polymer. Since the PS matrix has the same properties as the grafted layer, the reinforcement effect is considered to be mainly supported by the nanotubes only. The best fit of the PS-g-CNx composite experimental results was obtained with the aspect ratio $f=80$ (C.f. Figure 3 ). The HK model fits well with experimental data for nanotubes concentrations up to 1 vol.\%. But for higher content, i.e. at 2.5 vol. $\%$ of PS-g-CNx, the material modulus is far from those obtained by the HK equation. It has been shown that for high volume fractions, CNx MWNTs might "saturate" the matrix ${ }^{12,16}$. Wang et al. $^{26}$ reported similar results for fractions above 1 vol. $\%$ in a polyethylene matrix: a high volume fraction of MWNTs may even lead to a decrease of the mechanical properties of the nanotube composite. They impute this phenomenon to the appearance of aggregates. In this case, the tubes cannot be considered as perfectly dispersed, and consequently they do not follow Halpin Kardos hypothesis where particles are individually embedded in the matrix. Furthermore at increasing its volume fraction, the nanotubes must be more curved due to strong interactions with their neighbors. In that case, a decreased shape factor might be considered to account for this increasing waviness. Thus, at low nanotube content, the reinforcement is the same as the one of 5 time shorter rigid rods. This confirms the impact of CNTs waviness upon composite reinforcement ${ }^{27,28}$. As a second attempt, we fit the experimental data with the true shape factor, considering the $\mathrm{CN}_{\mathrm{X}}$ MWNTs Young modulus as an adjustable parameter. The best fit for an aspect ratio of 400 was obtained for longitudinal nanotube modulus of $240 \mathrm{GPa}$. Again, it is clear that the theoretical modulus value of $750 \mathrm{GPa}$ cannot be used since the nanotubes, when dispersed in a polymeric matrix, are not perfectly stretched ${ }^{29}$. For example, Coleman et al. ${ }^{30}$, using Krenchel's rule 
of mixture showed that catalytically grown MWNTs have an effective modulus of 190 GPa which is close to the value of $240 \mathrm{GPa}$ used here for our fit. Both attempts to model our data using the HK equations are not representative of our system. Nevertheless, it highlights the effect of the carbon nanotubes waviness. Thus, according to the first attempt, a twisted nanotube may appear as equivalent to a set of independent straight segments with an average length equal to $1 / 5$ of the original nanotube length.

\section{Dynamic Mechanical analysis: of PS /CNx MWNTs composites}

In torsion mode, the sample stiffness accuracy highly depends of the precision on the sample thickness determination which can lead to strong uncertainty on the absolute value of the shear modulus. In order to overcome to this problem DMA curves were calibrated from the compressive test data. All the results are presented in Figure 4 and Figure 5. Measurements were performed in the range of $300 \mathrm{~K}$ up to $500 \mathrm{~K}$.

\section{$\underline{\alpha \text { Transition temperature }}$}

Both types of composites exhibit a decrease of the tan $\delta$ peak at increasing volume fraction of $\mathrm{CNx}$ MWNTs (Figure $4 \mathrm{~b}$ and Figure $5 \mathrm{~b}$ ). The a-CN $\mathrm{CN}_{\mathrm{X}}$ nanocomposites (with 0 to 2.5 vol.\% of $\mathrm{CN}_{\mathrm{X}}$ MWNTs) exhibit a relative stability of the $\tan \delta$ peak temperature, called hereafter as T $\alpha$, and measured at $385 \mathrm{~K}$. This is in agreement with calorimetric measurements that do not exhibit any effect of a-CN $\mathrm{C}_{\mathrm{X}}$ MWNTs on the matrix Tg (C.f. Figure 1). Results obtained for PS-g-CNx / PS nanocomposites exhibit a different behavior. Contrary to the theory of limited macromolecular mobility near to the nano-fillers surface ${ }^{11,13}$, we observed a shift of T $\alpha$ toward the lower temperatures at increasing fraction of PS-g-CNx (2.5 vol. \% PS-g-CNx, T $\alpha=379.8 \mathrm{~K})$. This result is consistent with the DSC experiments, and suggests an increase of the molecular mobility. Furthermore, the position and the broadness of the tan $\delta$ peak for 2.5 vol.\% PS-g-CN ( $_{\mathrm{X}}$ (shifted toward lower temperatures) indicates that most of the PS matrix has a higher molecular mobility than the original PS. This confirms that almost all the matrix is in close contact with the nanotubes, which corroborate our previous conclusion about the enhanced dispersion of polymer grafted nanotubes. 
Above the glass transition temperature, the storage shear modulus of both nanocomposites presents different evolutions. Figure $4 \mathrm{a}$ shows that by increasing the quantity of a-CNx the temperature $\mathrm{T}_{\mathrm{d}}$, (material flowing temperature) increases. Therefore, above 0.25 vol. $\%$ of a-CNx, the materials do not flow over the experiment temperature window $(\operatorname{Tmax}=500 \mathrm{~K})$, whereas pure PS flows at $420 \mathrm{~K}$. PS-g-CNx nanocomposites reveal a weaker flowing thermal resistance (cf. Figure 5b). Most of the PS-g-CNx composites have a flowing temperature comparable to the pure PS one (420 K), except the sample with 2.5 vol. $\%$ of PS-g-CNx for which $T_{d}$ starts to increase $\left(T_{d}=460 \mathrm{~K}\right)$. In a previous study we have already shown that these CNx MWMTs composites exhibit an electrical percolation threshold at $0.4 \mathrm{vol} \%{ }^{31}$. A similar rheological analysis of liquid polymers filled with MWNTs demonstrated that above the percolation threshold a "solid-gel" transition is observed ${ }^{10,23}$. Meincke et al. $^{23}$ assume that this phenomenon is due to a mechanical percolating network formed by interlocked tubes. Moreover, it has been shown ${ }^{32}$ that nanotubes dispersed in poly(styrene-co-butyl acrylate) can form a mechanical percolating network if the nanotubes are entangled. They also reported that a simple contact between nanotubes (without entanglements) is not sufficient to increase the flowing temperature of the nanocomposites, which is easily understandable since the nanotube interact each other through weak van der Waals forces. Concerning the PS-g-CNx composites, the grafted polymer layer has a temperature dependent behavior. Above its glass transition temperature (lower than $\mathrm{Tg}$ of the pure PS matrix) the viscosity near the tube surface decreases allowing the nanocomposite to flow more easily than for a-CNx composites. In that case, we expect the disentanglement of nanotubes to be easier, and the interface may play the role of a lubricant.

\section{Pseudo plateau characteristics: storage modulus}

From DMA experiments, the storage shear modulus of the different materials at $420 \mathrm{~K}$ is plotted versus the filler volume fraction. In Figure 6, they are compared with the Halpin Kardos model using the same parameters as those obtained previously (CNT Young's modulus $=750 \mathrm{GPa}, \mathrm{f}=80$ ). For CNTs volume fractions less than 0.5 vol. $\%$, the storage shear modulus of both type of composites is 
in good agreement with the theoretical prediction from the Halpin Kardos model, whenever higher CNTs volume fractions exhibit larger modulus than that expected by the HK equation. Indeed, the deviations of the mechanical behavior are in agreement with the previous discussion about entangled fibers, thus corroborating the results obtained on the flowing temperatures. We believe that above the percolation threshold, nanotubes entanglements contribute strongly to the composite stiffening particularly when the polymer is almost a liquid ${ }^{32}$. Thus, the Halpin-Kardos model, which does not account for filler-filler interactions, underestimates the experimental data. Notice that PS-g-CNx composites are less stiff than a-CNx MWNTs composites. As previously discussed, the lubricant effect of the PS grafted layer makes easier the disentanglements of nanotubes.

\section{Large strain deformation of PS/CNx MWNTs nanocomposites}

As mentioned above, at ambient temperature, the grafting of polystyrene on the external layer of CNx MWNTs increase the adhesion between nanotubes and matrix. A strong interface adhesion can even lead to an alignment of the carbon nanotubes along the strain direction during a tensile test ${ }^{33}$. On the contrary, some authors who used untreated nanotubes reported that the fracture can propagate through the weak interface between the carbon nanotubes and the matrix ${ }^{34}$. In Figure 7 , a fracture surface of the $2.5 \%$ vol. CNx MWNTs/PS nanocomposites is observed at higher magnification (than in Figure 2). PS-g-CNx's (Figure 7a) seem to have been broken with short end, perpendicular to the fracture surface. The tubes were cut (pointed out by white circles) meaning that the adhesion at the PS-g-CNx / PS interface is strong enough to propagate the fracture through the nanotube and not along the tubes. On the contrary, a-CNx's seem to lie on the fracture surface (Figure 7b), as if they were pulled out during the crack propagation. The black circles focus on the presence of pulled-out tubes and holes, which confirm the poor adhesion between a-CN $\mathrm{C}_{\mathrm{x}}$ and PS. The two mechanisms of fracture propagation are schematically summarized in Figure 7. Results of compression tensile tests on nanocomposites are shown in Figure 8. It is noteworthy that the addition of CNx MWNTs increases the yield stress in both cases. For nanocomposites with 2.5 vol. $\%$ of a-CNx the yield stress increases by $12 \%$, whereas it increases by $20 \%$ with 2.5 vol.\% of PS-g-CNx. At higher strain amplitude, i.e. for $\varepsilon>15 \%$, the experimental curves exhibit two different behaviors for as produced 
tubes and for grafted tubes. For a-CNx's, the stress appears to remain constant at increasing deformation, whereas a significant hardening phenomenon appears for PS-g-CNx's at increasing nanotubes fraction. The hardening is a complex phenomenon that is still being investigated. In pure polymers, it is often observed ${ }^{35}$. Concerning composites or nanocomposites, it is pointed out that the appearance of damage that initiates at the beginning of the steady state stress may compensate for the hardening which is expected to be even stronger than for the pristine matrix ${ }^{36}$. One can also speculate about the role of the nanotubes entanglements which could contribute for to the hardening of such composites. It is reported that the main reinforcement phenomenon for as produced nanotubes composites is essentially due to local shear stress at the interface nanotubes matrix ${ }^{37}$. As mentioned above, the addition of a-CNx does not have any effect on the PS matrix plastic properties. It suggests that at the yield stress, the a-CNx / PS interface starts to delaminate and consequently the matrix/nanotube load transfer is not anymore active (damage effect). Thus, for as-produced CNx MWNTs the activation of pull-out phenomenon appears at the matrix yield stress, and permits the release of internal stresses by nanotube sliding through the matrix. On the contrary, we believe that the polymer grafting permits the composite to partly avoid the interface breaking even for high strain. The hardening behavior observed on Fig. 8 (bottom) may be because the grafting almost avoids the pull out phenomenon.

\section{$\underline{\text { Conclusions }}$}

We have shown that the introduction of as-produced N-doped multiwall carbon nanotubes in a polystyrene matrix results in weak increases of the matrix elastic properties. Nevertheless at low temperatures (below $\mathrm{Tg}$ of the PS matrix), the grafted polystyrene leads to an increase of the reinforcing effect, on both the material stiffness and on its failure stress. The grafting permits a more homogeneous dispersion of the carbon nanotubes within the polystyrene matrix. Furthermore the covalent bonds between the grafted polymeric chains and the carbon nanotube surface permit a stronger filler/matrix interface. On the other hand, at high temperatures (above Tg of the PS matrix), the rubbery plateau is less pronounced for composites using polystyrene grafted nanotubes. The low molecular weight of the grafted polystyrene plays the role of a plasticizer with the surrounding 
matrix and acts as a lubricant that makes nanotubes disentanglements easier. This work suggests that the grafting of polymer on the nanotubes efficiently modifies the matrix/filler interactions. Among the numerous questions on the interface role, the one related on the molecular weight effect of the grafted polymeric chains is still a key question. Finally, we also demonstrated that polymer grafting induces significant changes during plastic deformation mechanism.

\section{$\underline{\text { References }}$}

1. Harris P. J. F. Carbon Nanotubes and Related Structures- New Materials for the Twenty-First Century. Cambridge University Press, 1999

2. Poncharal P, Wang ZL, Ugarte D, de Heer WA. Electrostatic Deflections and Electromechanical Resonances of Carbon Nanotubes. Science, 1999; 283:1513-16

3. Balasubramanian K., Burghard M. Chemically Functionalized Carbon Nanotubes. Small, 2005; 1(2):180-192

4. Banerjee S, Hemraj-Benny T and Wong SS. Covalent surface chemistry of single-walled carbon nanotubes. Advanced Material, 2005; 17(1):17-29

5. Lin Y, Zhou B, Fernando KAS, Liu P, Allard LF, Sun YP. Polymeric carbon nanocomposites from carbon nanotubes functionalized with matrix polymer. Macromolecules, 2003; 36(19):7199-04

6. Matyjaszewski K, Xia J. Atom Transfer Radical Polymerization. Chemical Reviews, 2001; 101:2921-90

7. Fragneaud B, Masenelli-Varlot K, Gonzalez-Montiel A, Terrones M, Cavaille JY. Efficient Coating of N-Doped Carbon Nanotubes with Polystyrene using Atom Transfer Radical Polymerization. Chemical Physics Letters, 2006; 419(4-6):567-573

8. Breton Y, Desarmot G, Salvetat JP, Delpeux S, Sinturel C, Beguin F, Bonnamy S. Mechanical properties of multiwall carbon nanotubes/epoxy composites: influence of network morphology. Carbon, 2004; 42(5-6):1027-30

9. Jiang XW, Bin YZ, Matsuo M. Electrical and mechanical properties of polyimide-carbon nanotubes composites fabricated by in situ polymerization. Polymer, 2005; 46(18):7418-24

10. Song YS, Youn JR. Properties of Epoxy Nanocomposites filled with Carbon Nanomaterials. ePolymers, 2004; 80

11. Sung YT, Kum CK, Lee HS, Byon NS, Yoon HG, Kim WN. Dynamic mechanical and morphological properties of polycarbonate/multi-walled carbon nanotube composites. Polymer, 2005; 46(15):5656-61 
12. Tai NH, Yeh MK and Liu JH. Enhancement of the mechanical properties of carbon nanotube / phenolic composites using a carbon nanotube network as the reinforcement. Carbon, 2004; 42(12-13):2774-77

13. Velasco-Santos C, Martinez-Hernandez AL, Fisher F, Ruoff R, Castano VM. Dynamicalmechanical and thermal analysis of carbon nanotube-methyl-ethyl methacrylate nanocomposites. Journal of Physics D: Applied Physics, 2003; 36(12):1423-28

14. Cadek M, Coleman JN, Barron V, Hedicke K, Blau WJ. Morphological and mechanical properties of carbon-nanotube-reinforced semicrystalline and amorphous polymer composites. Applied Physics Letters, 2002; 81(27):5123-25

15. Coleman JN, Khan U, Blau WJ, Gun'ko YK. Small but strong: A review of the mechanical properties of carbon nanotube-polymer composites. Carbon, 2006; 44(9):1624-52

16. Valentini L, Biagiotti J, Kenny JM, Manchado MAL. Physical and mechanical behavior of single-walled carbon nanotube/polypropylene/ethylene-propylene-diene rubber nanocomposites. Journal of Applied Polymer Science, 2003; 89(10):2657-63

17. Odegard GM, Gates TS, Wise KE, Park C, Siochi EJ. Constitutive modeling of nanotubereinforced polymer composites. Composites Science and Technology, 2003; 63(11):1671-87

18. Viswanathan G, Chakrapani N, Yang HC, Wei BQ, Chung HS, Cho KW, Ryu CY, Ajayan PM. Single-step in situ synthesis of polymer-grafted single-wall nanotube composites. Journal of the American Chemical Society, 2003; 125(31):9258-59.

19. Kumar S, Dang TD, Arnold FE, Bhattacharyya AR, Min BG, Zhang XF, Vaia RA, Park C, Adams WW, Hauge RH, Smalley RE, Ramesh S, Willis PA. Synthesis, structure, and properties of PBO/SWNT composites. Macromolecules; 2002, 35(24):9039-43.

20. Terrones M, Kamalakaran R, Seeger T, Ruhle M. Novel nanoscale gas containers: encapsulation of N2 in CNx nanotubes. Chemical Communications, 2000; (23):2335-36

21. Etienne S, Cavaille JY, Perez J, Point R, Salvia M. Automatic System for Analysis of Micromechanical Properties. Review of Scientific Instruments, 1982; 53(8):1261-66.

22. Williams ML, Landel RF \& Ferry JD. The temperature dependence of relaxation mechanisms in amorphous polymers and other glass-forming liquids. Journal American Chemical Society, 1955; $77: 3701-7$

23. Meincke O, Kaempfer D, Weickmann H, Friedrich C, Vathauer M, Warth H. Mechanical properties and electrical conductivity of carbon-nanotube filled polyamide- 6 and its blends with acrylonitrile/butadiene/styrene. Polymer, 2004; 45(3):739-748

24. Halpin JC and Kardos JL. Moduli of crystalline polymers employing composite theory. Journal of Applied Physics, 1972; 43(5):2235-41

25. Hernandez E, Goze C, Bernier P, Rubio A. Elastic Properties of C and BxCyNz Composite Nanotubes. Physical Review Letters, 1998; 80(20):4502-05 
26. Wang YP, Cheng RL, Liang LL, Wang YM. Study on the preparation and characterization of ultra-high molecular weight polyethylene-carbon nanotubes composite fiber. Composites Science and Technology, 2005; 65(5):793-797

27. Fisher FT, Bradshaw RD, Brinson LC. Fiber waviness in nanotube-reinforced polymer composites-1: Modulus predictions using effective nanotube properties. Composites Science and Technology, 2003; 63(11):1689-1703.

28 Bradshaw RD, Fisher FT, Brinson LC. Fiber waviness in nanotube-reinforced polymer composites-II: modeling via numerical approximation of the dilute strain concentration tensor. Composites Science and Technology, 2003; 63(11):1705-22.

29 Dalmas F, Chazeau L, Gauthier C, Masenelli-Varlot K, Dendievel R, Cavaillé JY, Forro L. Multiwalled carbon nanotube/polymer nanocomposites: Processing and properties. Journal of Polymer Science. Polym. Phys., 2005; 43(10):1186-1197

28. Coleman JN, Cadek M, Blake R, Nicolosi V, Ryan KP, Belton C, Fonseca A, Nagy JB, Gun'ko YK, Blau WJ. High-performance nanotube-reinforced plastics: understanding the mechanism of strength increase. Advanced Functional Materials, 2004; 14(8):791-798

29. Fragneaud B, Masenelli-Varlot K, Gonzalez-Montiel A, Terrones M, Cavaille JY. Electrical behavior of polymer grafted nanotubes/polymer nanocomposites using N-doped carbon nanotubes. Chemical Physics Letters, 2007; 444(1-3):1-8.

30. Dalmas F, Cavaillé JY, Gauthier C, Chazeau L, Dendievel R, Remy. Viscoelastic behavior and electrical properties of flexible nanofiber filled polymer nanocomposites. Influence of processing conditions. Composites Science and Technology, 2007; 67(5):829-839

31. Hwang GL, Shieh YT, Hwang KC. Efficient load transfer to polymer-grafted multiwalled carbon nanotubes in polymer composites. Advanced Functional Materials, 2004; 14(5):487-491

32. Andrews R and Weisenberger MC. Carbon nanotube polymer composites. Current Opinion in Solid State \& Materials Science, 2004; 8(1):31-37

33. Mangion MBM, Cavaille JY, Perez J. A molecular theory for the sub-Tg plastic mechanical response of amorphous polymers. Philosophical Magazine A, 1992; 66(5):773-96

34. Chazeau L, Cavaille JY, Perez J. Plasticized PVC reinforced with cellulose whiskers. II. Plastic behavior. Journal Polymer Science, Polymer Physics, 2000; 38(3):383-92

35. Zhang X, Liu T, Sreekumar TV, Kumar S, Hu XD, Smith K. Gel Spinning of PVA/SWNT Composite Fiber. Polymer, 2004; 45(26):8801-8807 
Table 1: Experimental Young modulus obtained from linear elastic domain of compression tests

\begin{tabular}{cc|cccc|ccccc}
\hline \multirow{2}{*}{ Materials } & \multirow{4}{*}{ pure PS } & \multicolumn{5}{c|}{$\mathrm{a}-\mathrm{CNx} /$ vol.\% } & \multicolumn{5}{c}{ PS-g-CN $/$ vol.\% } \\
\cline { 3 - 10 } & & 0.05 & 0.25 & 0.5 & 2.5 & 0.05 & 0.25 & 0.5 & 1 & 2.5 \\
\hline Young Modulus $/ \mathrm{GPa}$ & \multirow{2}{*}{2.02} & 2.3 & 2.3 & 2.1 & 2.5 & 2.04 & 2.15 & 2.25 & 2.62 & 2.72 \\
Uncertainty $\pm 0.1 \mathrm{GPa}$ & & & & & & & & & & \\
\hline
\end{tabular}


Mechanical behavior of polystyrene grafted carbon nanotubes...., by Fragneaud et al.

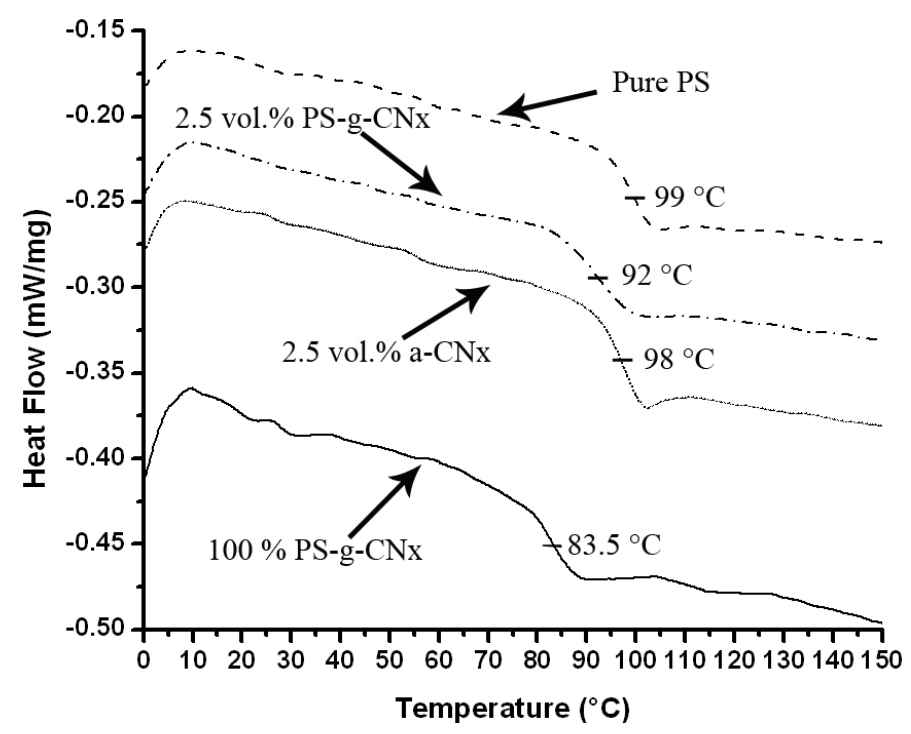

Figure 1: Glass transition observed by DSC. From top to bottom: PS matrix; 2.5 vol. \% PS-g$\mathrm{CNx} / \mathrm{PS}$ nanocomposite; 2.5 vol. $\%$ a-CN $\mathrm{X}_{\mathrm{X}} / \mathrm{PS}$ nanocomposites and finally pure PS-g-CNx
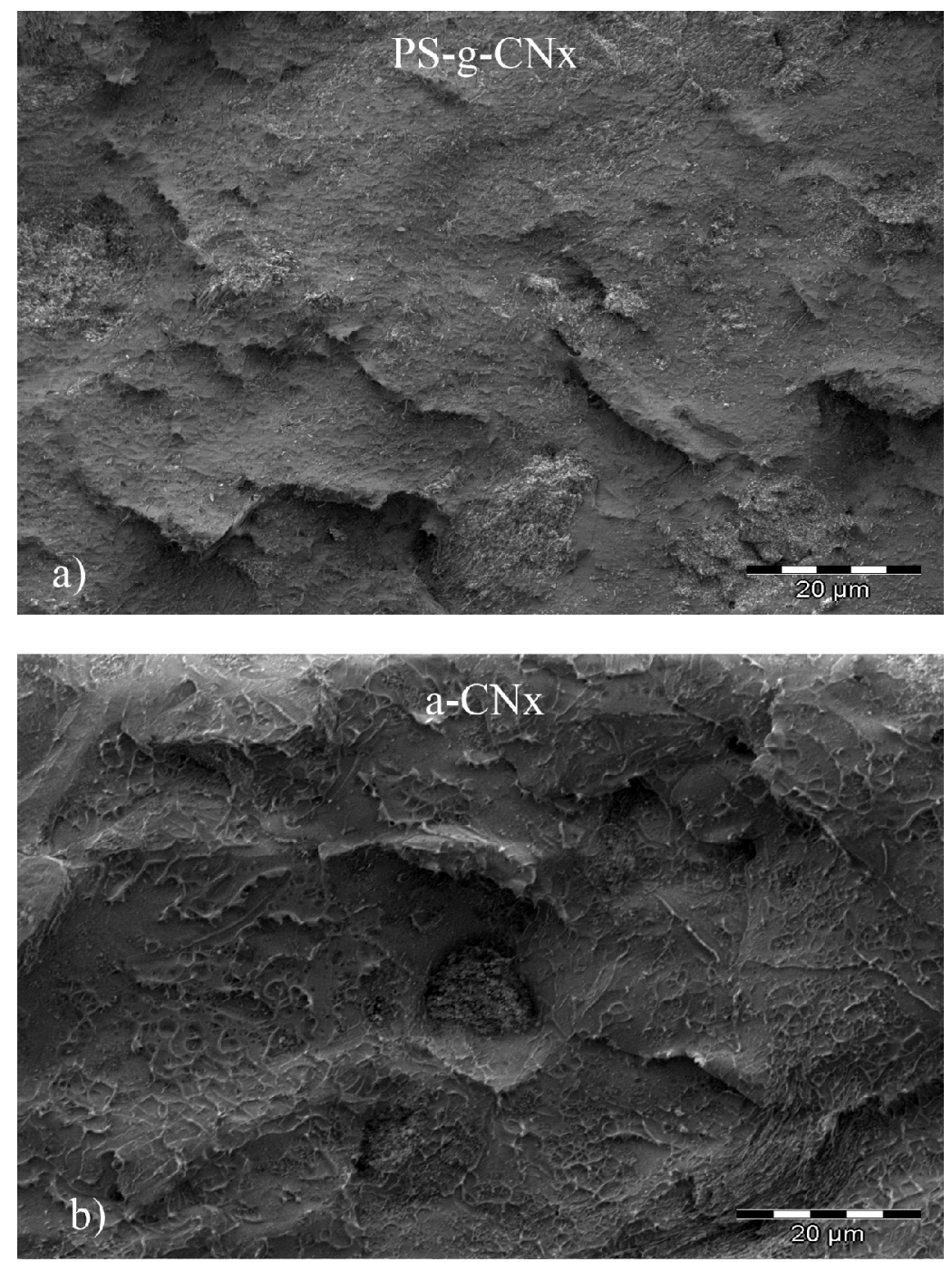

Figure 2: SEM low magnification photomicrographs of a) 2.5 vol.\% PS-g-CNx /

polystyrene nanocomposites and, b) 2.5 vol. \% a-CNx / polystyrene nanocomposites. 


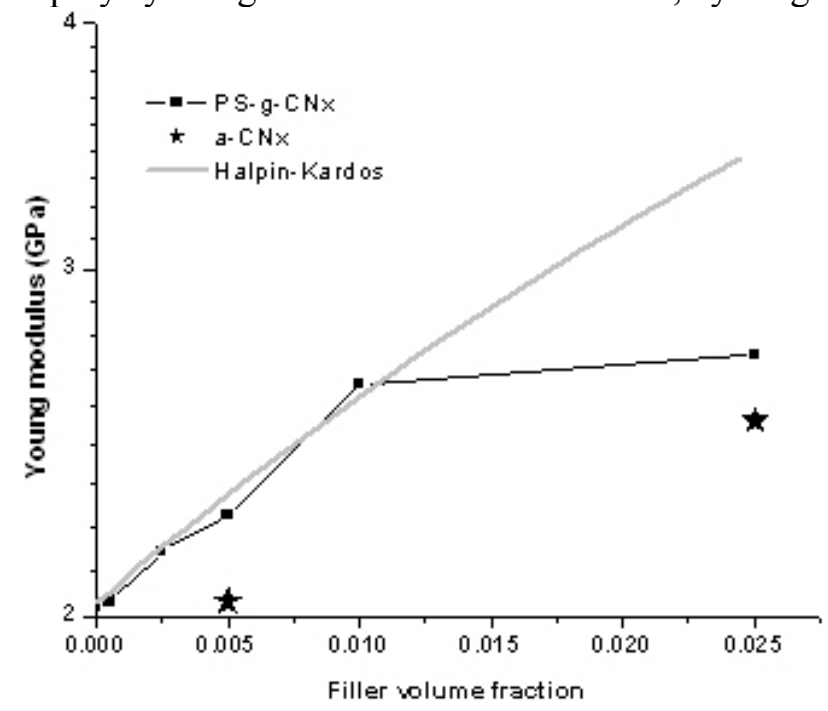

Figure 3: ( $\star$ ) experimental Young modulus for a-CNx nanocomposites; ( $\boldsymbol{\square}$ ) PS-g-CNx nanocomposites; (full line) theoretical results from the Halpin Kardos equation.
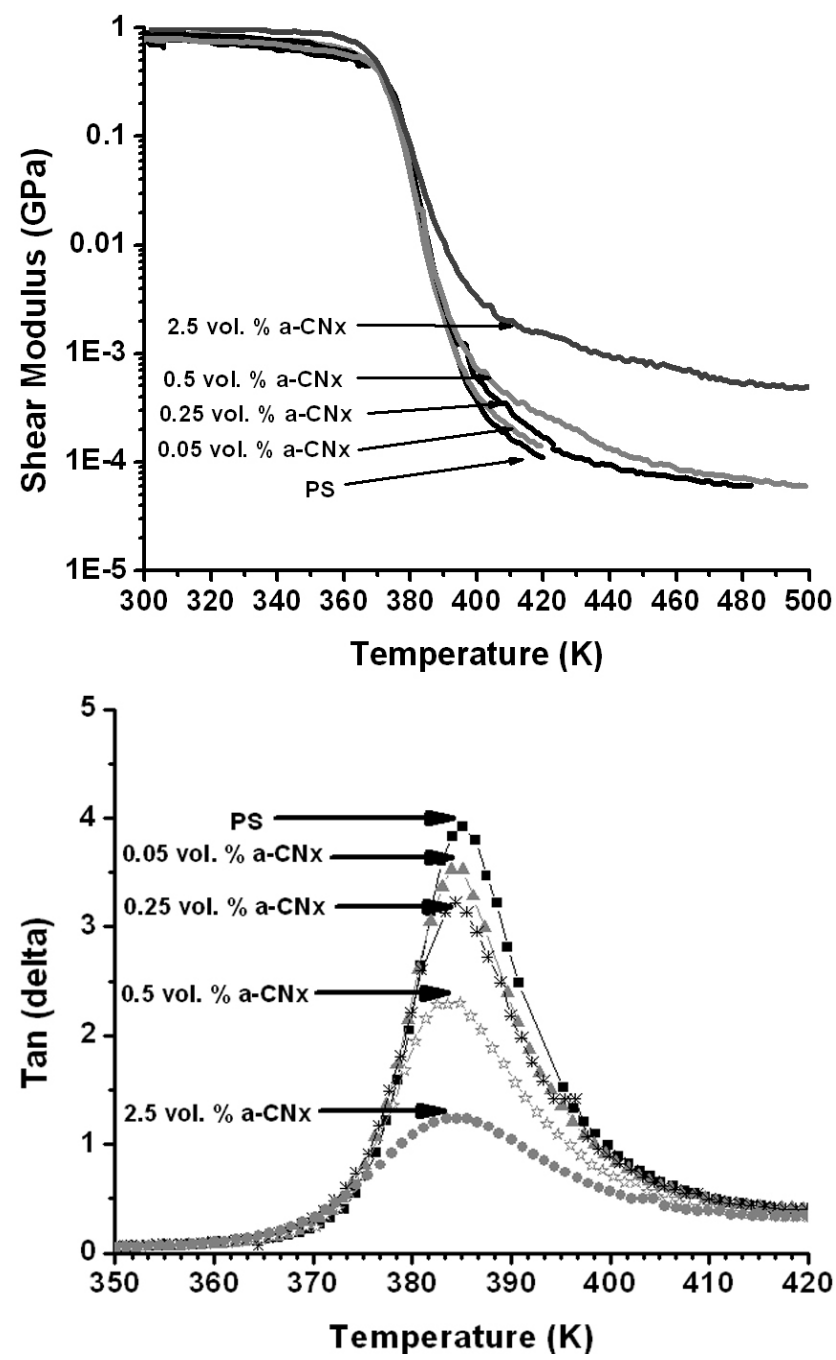

Figure 4: DMA data for a-CNx / PS composites, a) storage shear modulus versus temperature and $b$ ) tangent of the loss angle versus temperature 

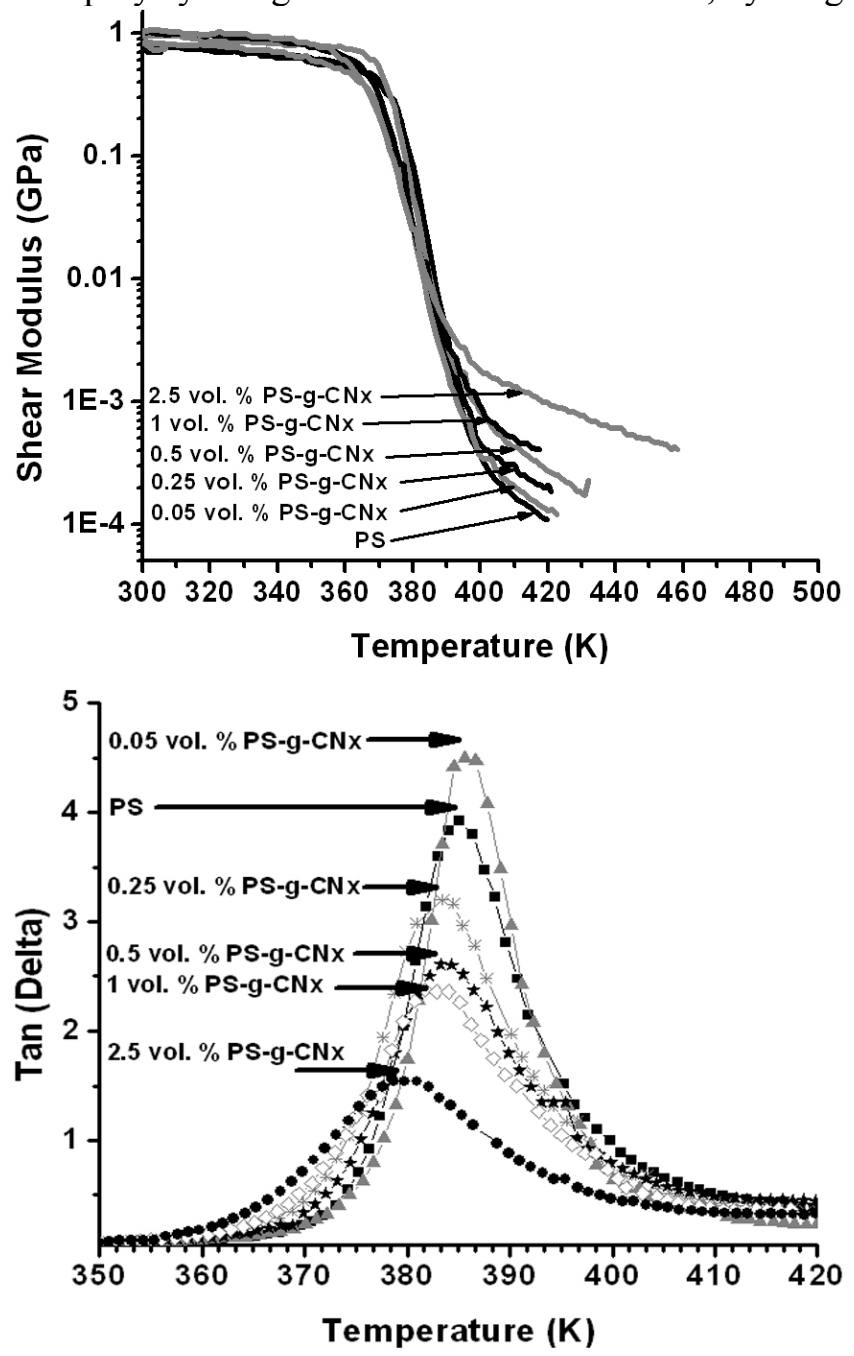

Figure 5: DMA data for PS-g-CNx / PS composites, a) storage shear modulus versus temperature and b) tangent of the loss angle versus temperature.

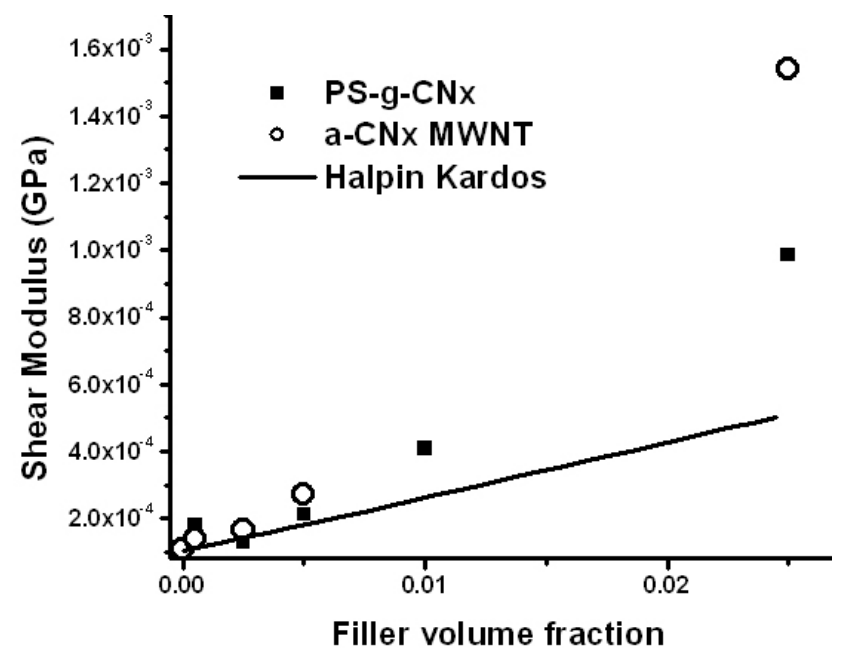

Figure 6: shear storage modulus at $420 \mathrm{~K}$ of PS filled with a-CNx MWNTs (O) and PSg-CNx MWNTs (•); shear modulus from the Halpin Kardos equation (-). 

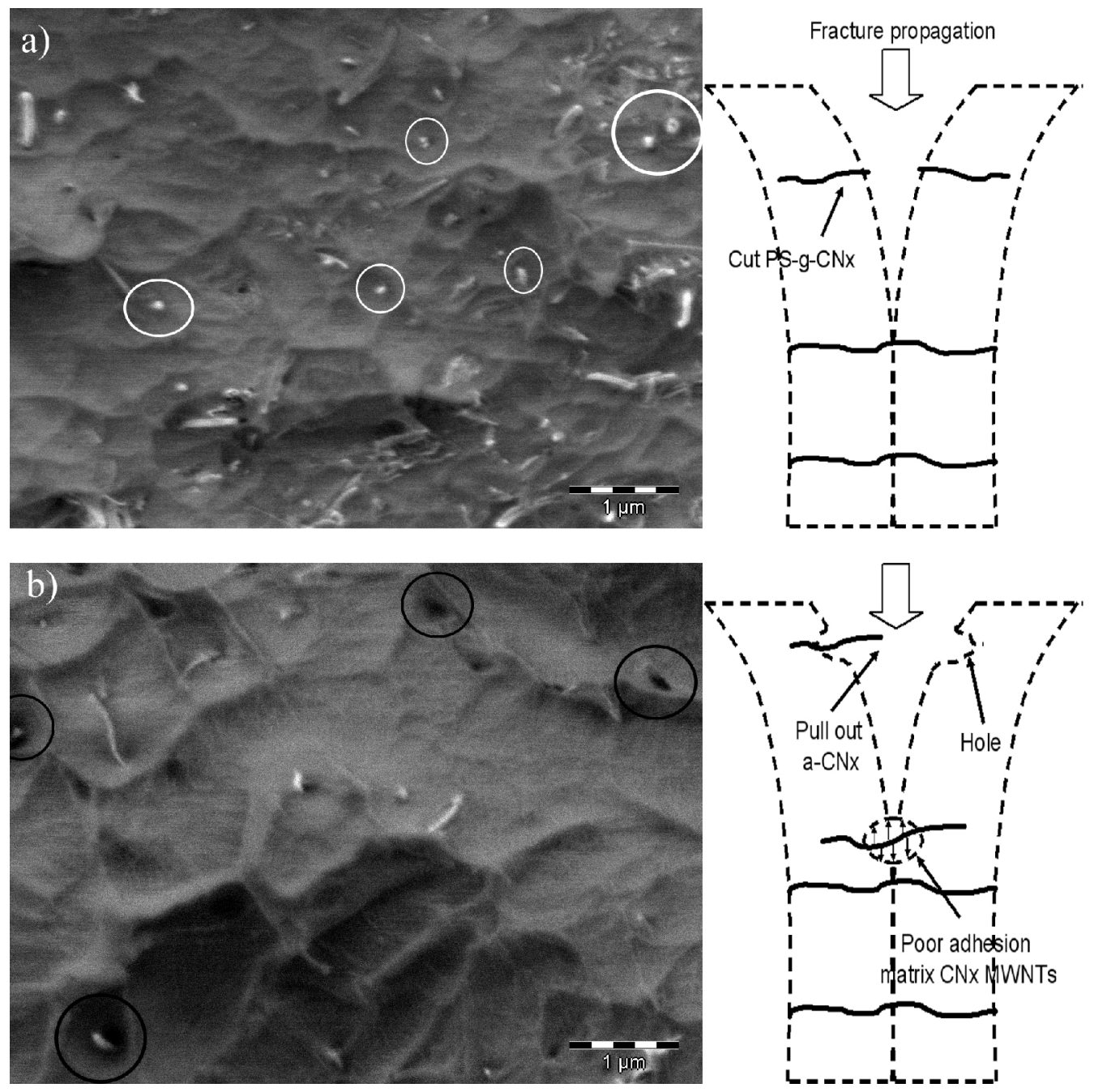

Figure 7: SEM micrographs of fracture surface; a) 2.5 vol.\% PS-g-CN $\mathrm{N}_{\mathrm{x}}$ : white circles focus on cut tubes; b) 2.5 vol. $\%$ a- $\mathrm{CN}_{\mathrm{x}}$ : black circles indicate holes or pulled out tubes. On the right: proposed corresponding fracture mechanisms. 

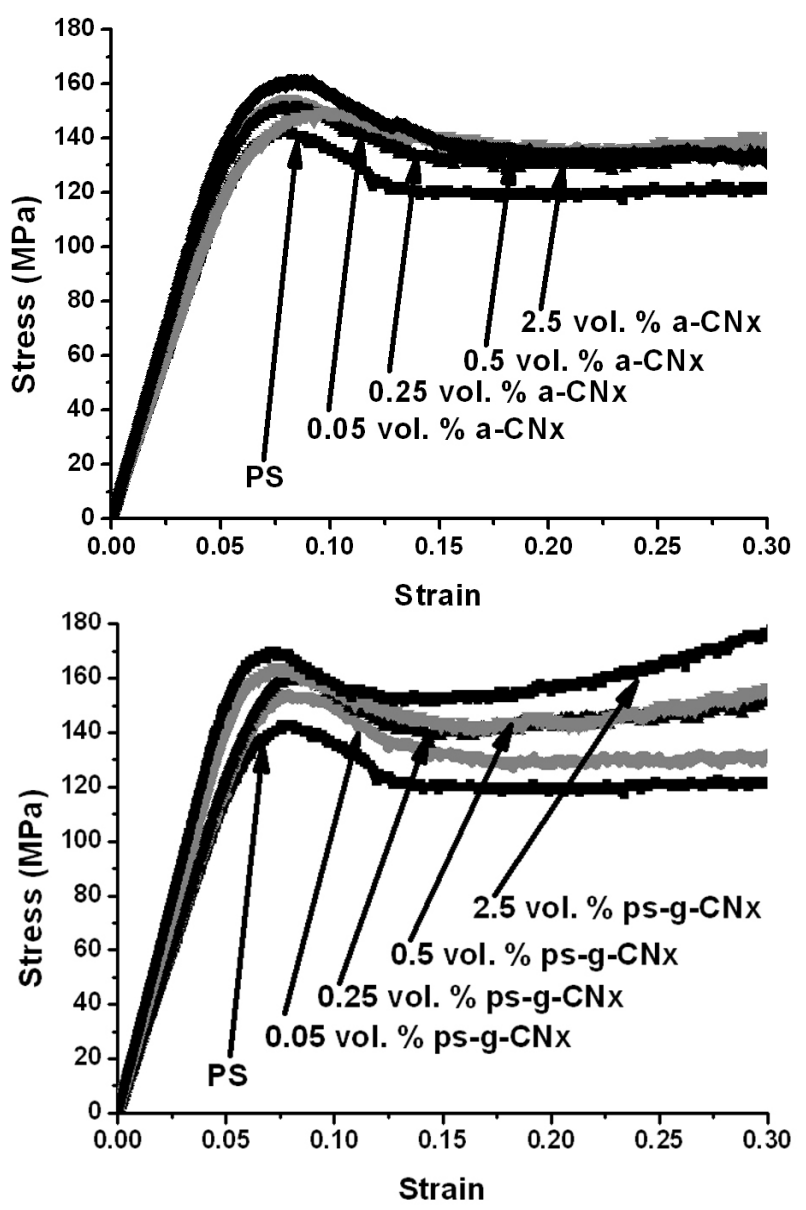

Figure 8: Compression tests for composites with: top, a-CNx,; bottom, PS-g-CNx 